\title{
Femtosecond Laser-Induced Saturable Absorption and Optical Limiting of Hollow Silver Nanocubes: Implications for Optical Switching and Bioimaging
}

Bhavesh Kumar Dadhich, ${ }^{1}$ Sayantan Bhattacharya, ${ }^{2}$ Swastik Ballav, ${ }^{2}$ Bhavya Bhushan, ${ }^{1}$ Prasanta Kumar Datta, ${ }^{2}$ and Amiya Priyam ${ }^{3, *}$

*Corresponding Author: Email: apriyam@cub.ac.in

S1. Synthesis of hollow plasmonic silver nanocubes and nanospheres.

Table S1: Synthesis conditions for SAgNPs and HAgNCs.

\begin{tabular}{|l|l|l|l|l|l|}
\hline $\begin{array}{l}\text { SPR peak } \\
(\mathrm{nm})\end{array}$ & Sample Name & $\begin{array}{l}\text { Temperature } \\
\left({ }^{\circ} \mathrm{C}\right)\end{array}$ & $\begin{array}{l}\text { Ag: FA molar } \\
\text { ratio }\end{array}$ & $\begin{array}{l}\text { Ag: HH molar } \\
\text { ratio }\end{array}$ & $\begin{array}{l}\text { Stirring } \\
\text { speed (rpm) }\end{array}$ \\
\hline 400 & SAgNP-400 & 20 & $1: 0.20$ & $1: 150$ & 225 \\
\hline 510 & HAgNC-510 & 50 & $1: 0.33$ & $1: 150$ & 0 \\
\hline 550 & HAgNC-550 & 50 & $1: 0.33$ & $1: 50$ & 225 \\
\hline 590 & HAgNC-590 & 50 & $1: 0.33$ & $1: 150$ & 225 \\
\hline 630 & HAgNC-630 & 50 & $1: 0.33$ & $1: 150$ & 180 \\
\hline
\end{tabular}




\section{Supporting Information}

S2. Structural and elemental analysis:
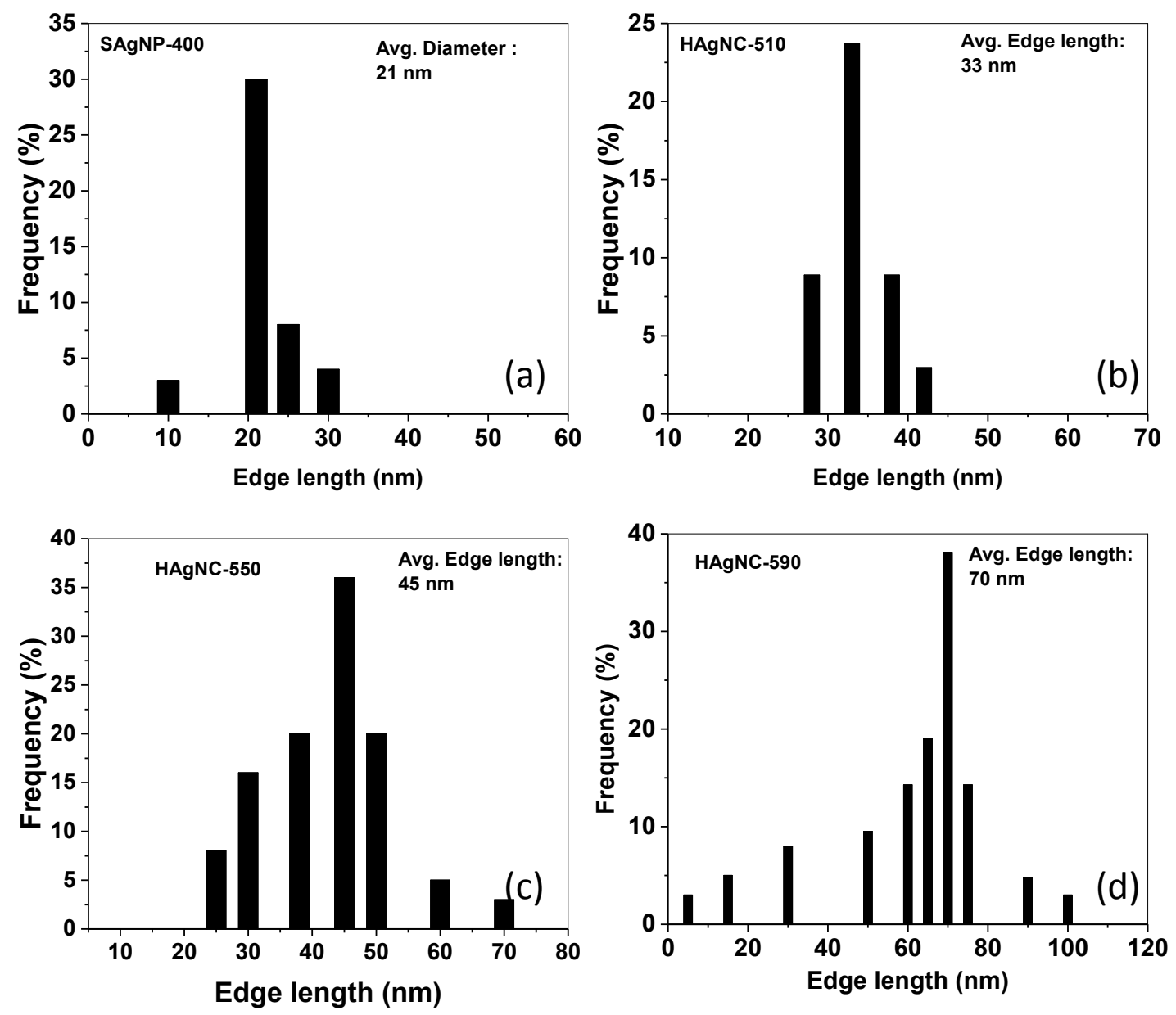

Figure S1. $(\mathrm{a} \rightarrow \mathrm{d})$ Size distribution histogram for SAgNP-400, HAgNC-510, HAgNC-550, and HAgNC-590.

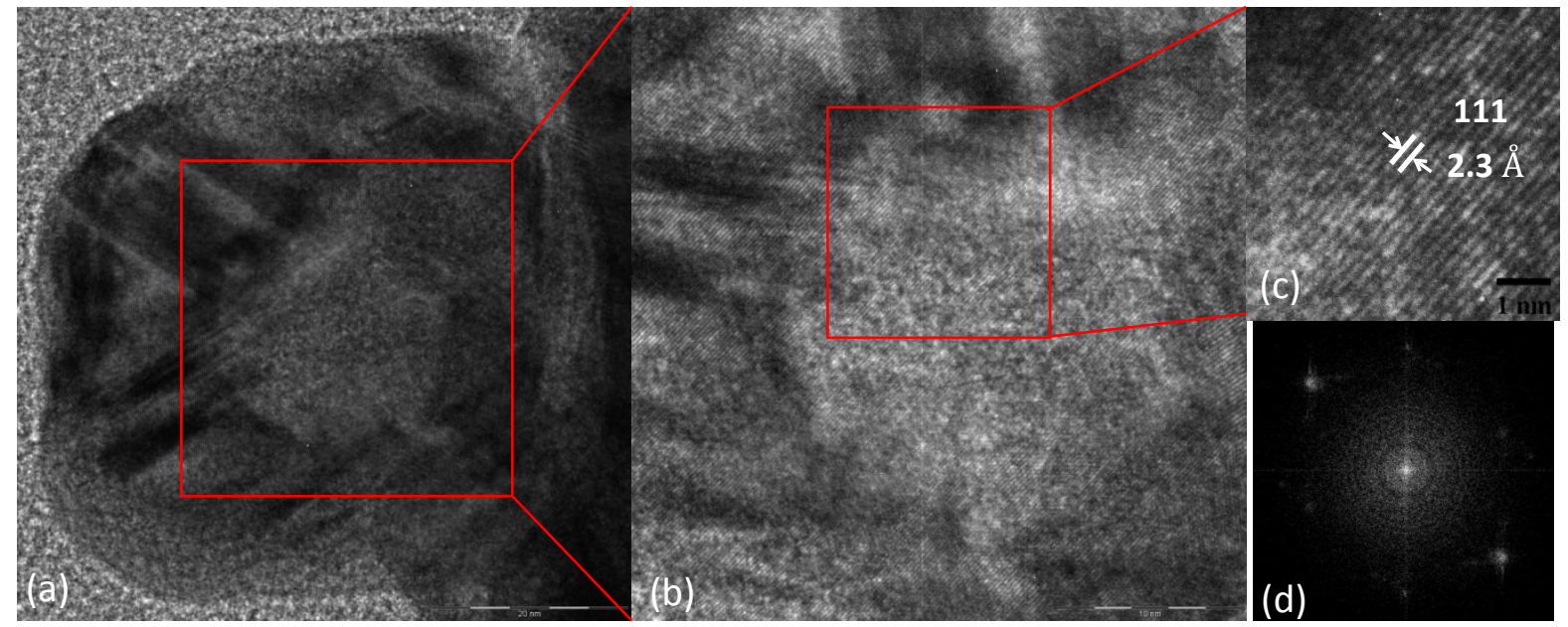

Figure S2. (a) HRTEM image of HAgNC-550 (b) central hollow part. (c) Zoomed-in view showing the lattice fringes. $\mathrm{d}=2.3 \AA$. The scale is $20 \mathrm{~nm}, 10 \mathrm{~nm}$, and $1 \mathrm{~nm}$ in a,b, and c respectively. (d) FFT of b, concentric rings are clearly visible in FFT. 


\section{Supporting Information}

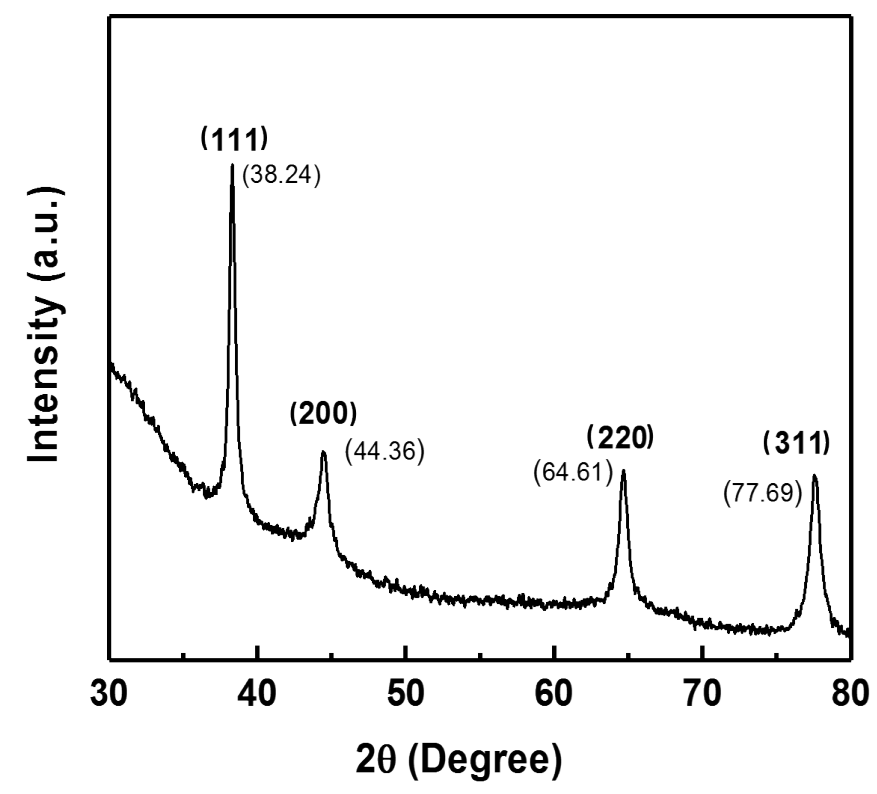

Figure S3. XRD pattern of HAgNC-590. All the peaks have been labeled for the corresponding hkl planes of fcc silver (JCPDS No. 04-0783) and $2 \theta$ values are given in parenthesis.

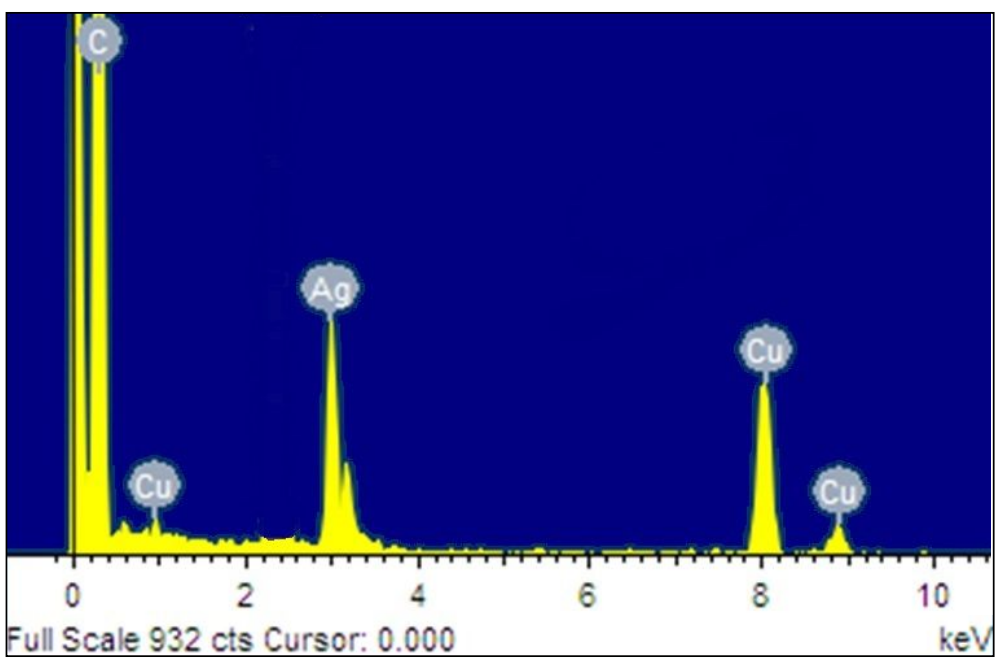

Figure S4. EDX spectrum of hollow silver nanocubes. 
S3. Nonlinear absorption (NLA) studies:

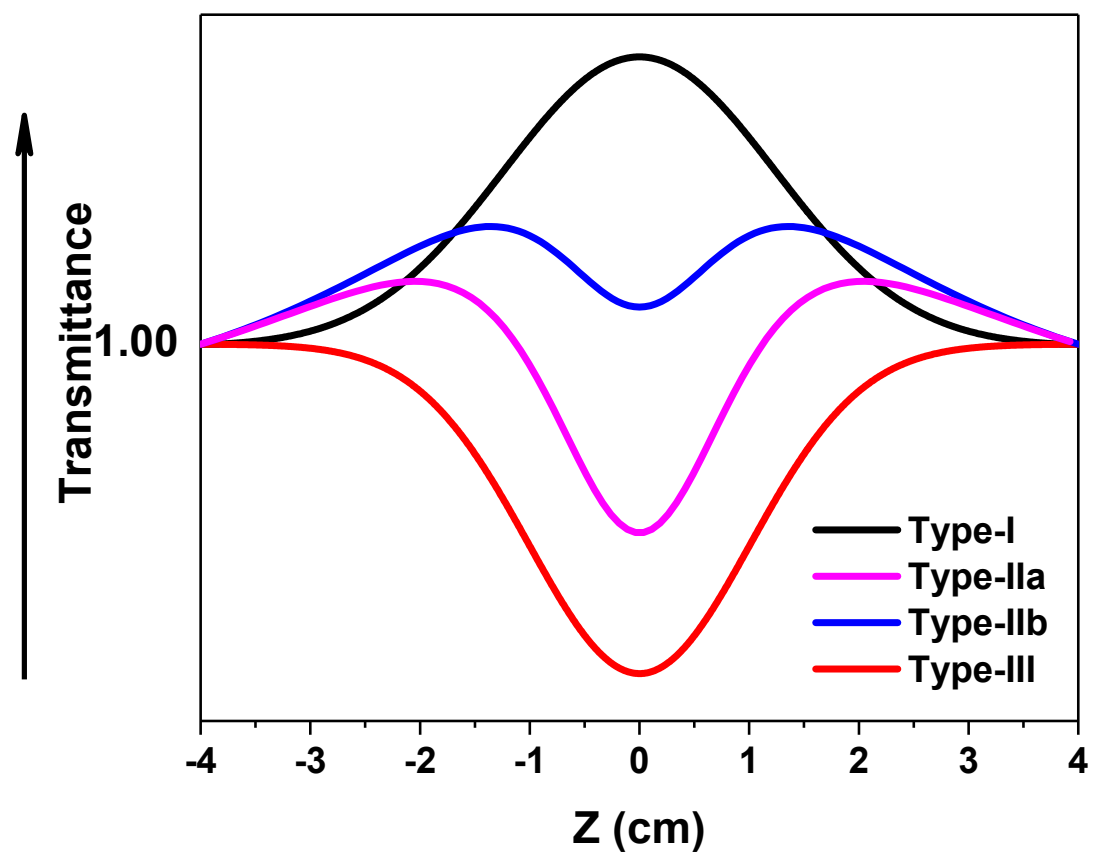

Figure S5. Different types of NLA curves.

Table S2. Different types of NLA curves in different samples.

\begin{tabular}{|c|c|c|c|c|}
\hline $\begin{array}{l}\text { Sample name } \\
\text { Laser Intensity }\end{array}$ & HAgNC-510 & HAgNC-550 & HAgNC-590 & HAgNC-630 \\
\hline $63 \mathrm{GW} / \mathrm{cm}^{2}$ & Type-I & Type-I & Type-I & Type-I \\
\hline $126 \mathrm{GW} / \mathrm{cm}^{2}$ & Type-IIa & Type-IIb & Type-I & Type-I \\
\hline $189 \mathrm{GW} / \mathrm{cm}^{2}$ & Type-IIa & Type-IIb & Type-IIb & Type-IIb \\
\hline $252 \mathrm{GW} / \mathrm{cm}^{2}$ & Type-III & Type-IIIa & Type-IIa & Type-IIa \\
\hline
\end{tabular}

Table S3. Contour electric field $(\mathrm{V} / \mathrm{m})$ for different nanocrystals.

\begin{tabular}{|l|l|l|}
\hline S.N. & Sample name & Contour Electric field (V/m) \\
\hline 1 & SAgNP-400 & 1.51 \\
\hline 2 & HAgNC-510 & 1.56 \\
\hline 3 & HAgNC-550 & 1.78 \\
\hline 4 & HAgNC-590 & 6.5 \\
\hline 5 & HAgNC-630 & 3.8 \\
\hline
\end{tabular}

